\title{
Design in Visual Communication
}

\author{
Mustafa Günay \\ Head of Design Department, Gelişim Vocational School, Istanbul Gelişim University, Istanbul, Turkey \\ Email: mgunay84@hotmail.com
}

How to cite this paper: Günay, M. (2021). Design in Visual Communication. Art and Design Review, 9, 109-122.

https://doi.org/10.4236/adr.2021.92010

Received: January 21, 2021

Accepted: April 5, 2021

Published: April 8, 2021

Copyright (c) 2021 by author(s) and Scientific Research Publishing Inc. This work is licensed under the Creative Commons Attribution International License (CC BY 4.0).

http://creativecommons.org/licenses/by/4.0/

\begin{abstract}
The art and visual communication design products also are significantly influenced by the development of technology, dissemination of means of communication and rapid advancement of consumption society. Along with the consumption society, serious changes started to occur in the interpretation and usage of art. Among the visual communication arts, absolutely the most important issue is the graphic design. The most prominent function of graphic design is to realize the introduction of a certain message or product by using visual expressions. Visual communication creates the same feeling and emotion without it being necessary to speak a certain language among all the people. The sense of sight is the most important sense organ for the humans. The incidents happening in the environment, the existing objects and situations are first identified upon being seen and tried to be understood. The information obtained through the sense of sight can be remembered more clearly than the information obtained via other senses. Therefore, it can be suggested for sure that seeing comes before speaking. In this study, the explorative research method has been utilized to investigate the concept of design in visual communication. The studies conducted previously by various researchers in various fields of visual communication were reviewed and the topic of design in visual communication was tried to be revealed based on the obtained findings. From this point onwards, it was found out that the importance of design in visual communication increased after the modern period and visual communication was benefitted from in many areas. Examining the point reached by design in visual communication today, it can be argued that such component is used very heavily on advertising and social media and even it has spread to every point which our eyes can see. Visual communication on the society and individuals had become a means of communication which is very widely used and needed today. It has been concluded that visual communication is applied in all activity areas of daily life and this situation has become highly important.
\end{abstract}

\section{Keywords}

Visual Communication, Design, Graphic Design 


\section{Introduction}

Design could be defined as a visual language which can construe the message desired to be transmitted or a problem desired to be solved through usage of visual components. Consequently, graphic design takes place among the visual arts.

Design is a visual language that describes the message to be transmitted with visual signs or solves the problem that is wanted to be solved using visual elements. Visual communication creates the same feeling and emotion among all the people, without it being necessary for speaking of a certain language. Therefore, graphic design is a visual art. The way the image of the object format we see is perceived at all points in the world is the same; it is a common language.

The most important skill in the phenomenon of communication is the language that people use to communicate with each other. Many different languages are used in many different regions of the world. There may be limitations, when these different languages interact with each other. Even though the language of visual communication is more limited, it is much more inclusive and unifying as it is universal. It can be said that, different from auditory system communication, messages generated in visual communication have more ability to maintain their permanence and effectiveness. This feature of visual communication ensures that it is permanent and used as a document.

It is very possible to say that all senses rely only on the sense of vision, and of all other senses, priority is given to the vision by people. Vision always has priority over speech for people. People learn to see before they start talking. The priority of the visual is as if it was riveted for humanity from the very first time.

The sense of sight is one of the most important senses. The events, existing objects and situations in the environment are defined by seeing them first and they are tried to be understood. Information obtained through the sense of sight is remembered more clearly than those obtained through other senses. For this reason, it can be easily stated that seeing comes before speaking.

From this point on, the importance of design in visual communication should be known where design comes from in post-modern visual communication. Visual communication has become a widely used and needed communication tool on society and individuals. This study was carried out in order to emphasize that visual communication is used in all activity areas in daily life and how important this situation is.

In this study, the explorative methods of research were benefitted from to investigate the concept of design in visual communication. The studies conducted previously by various researchers in various fields of visual communication were reviewed and the topic of design in visual communication was tried to be revealed based on the obtained findings.

Reviewing the design studies on visual communication which were conducted by different researchers in the previous periods, it is observed that the studies concentrated rather on the social or sociological aspect, but the graphic design 
component and the ways of behavior reflecting to the society have been neglected. It is believed that this current study which has been realized to address to this topic will complete a deficiency in the literature and this increases the importance of this study.

From this viewpoint, it was found out that the importance of design in visual communication increased after the modern period and visual communication was benefitted from in many areas. Examining the point reached by design in visual communication today, it can be argued that such component is used very heavily on advertising and social media and even it has spread to every point which our eyes can see.

Visual communication on the society and individuals had become a means of communication which is very widely used and needed today. It has been concluded that visual communication is applied in all activity areas of daily life and this situation has become highly important.

\section{Communication and Graphic Design}

\subsection{Communication}

There are many studies to better understand the nature of communication, which is an element at the heart of the hierarchy of needs (Eroğlu, 1996: p. 275). In these studies, communication in general, in its simplest form, is defined as the transmission of a message from a source to the recipient. Lasswell, an American political scientist, claimed in 1948 that the most appropriate way to define the concept of communication is to answer questions such as "Who?", "What does he/she/it say?”, “Through what channel?”, “To whom?”, "By what effect?” and thus, created perhaps the most famous basic communication model. The mathematical model of Shannon and Weaver also defined communication as a linear and one-way process (Han, 2014: p. 1).

All basic communication process steps should be included, no matter what type of communication; otherwise, communication process cannot reach the final stage. It is the sender who initiates the communication. The sender is required to determine the purpose of the communication. If the purpose of the communication is determined, the recipient's expectations will also be revealed. It is very difficult for messages, the purpose of which has not been determined, to have an impact on the recipient and achieve their goal (Becer, 2011: p. 14).

Media is the general name given to channels that transmits the message. The developing technology allows communication channels to increase rapidly. It determines the channel through which the message will be transmitted and plays an important role in ensuring the effective communication process. Communication designers have to determine the most effective media tool based on the message.

\subsection{Graphic Design}

Design is a visual language that describes the message to be transmitted with 
visual signs or solves the problem that is wanted to be solved using visual elements. Therefore, graphic design is a visual art (Çakır, 2014: p. 36). The way the image of the object format we see is perceived at all points in the world is the same; it is a common language (Öztuna, 2007: p. 42).

The graphic design mentioned produces visual meanings with the goal of conveying a message or specifying a product and service (Yücebaş, 2006: p. 3). Today, the graphic design existing in every aspect of our lives to street signs on the road, gives us information and direction and draws attention to a number of issues (Becer, 2011: p. 32).

Designers produce an interactive work to solve the visual problem that will be given to them as a problem by using the principles and elements of design (Erdal, 2006: p. 21). At this stage, basic design constitutes the most important source of creative and analytical thinking (Öztuna, 2007: p. 10).

It is known that the birth of graphic design as an art branch was based on cave paintings from before the early 20th century. This visual language, which is old enough to extend to cave paintings, is the basic building block of many areas (Atan, 2017: p. 6).

Graphic design, which means original design such as writing, drawing, duplicating, is "the application of painting and writing using complementary integrity with aesthetic qualities to deliver the message to the target through visual communication" (Arikan, 2009: pp. 9-10).

\section{Visual Communication and Visual Communication Design}

\subsection{Visual Communication}

Communication can be defined as the act of transferring information, ideas, thoughts or emotions from one place, person or group to another through speech, signals, writing, or behaviour (Becer, 2011: p. 11).

The most important skill in the phenomenon of communication is the language that people use to communicate with each other. Many different languages are used in many different regions of the world. There may be limitations, when these different languages interact with each other. Even though the language of visual communication is more limited, it is much more inclusive and unifying as it is universal. It can be said that, different from auditory system communication, messages generated in visual communication have more ability to maintain their permanence and effectiveness. This feature of visual communication ensures that it is permanent and used as a document (Uçar, 2004: p. 19).

All kinds of information exchanges and interactions between people are a communication. When this exchange is performed with visuals, it is called visual communication. Spoken language is used when transferring one emotion, thought and information to someone else (Kavuran \& Çetinkaya, 2012: p. 611). Our language of speech allow us to interact with people, in other words, to communicate. However, due to the fact that there are so many languages spoken in the world, the communication opportunities provided to us by our spoken language 
are limited. Parsa (2004) explains visual communication as "While the number of words of the spoken language is limited, the dictionary of images that make up the visual language is unlimited." Therefore, visual communication is more universal because it provides us with contact with people whose language we cannot speak (Arikan, 2009: p. 11).

Visual communication is the exchange of information created through the image between people without the need for words. The development of vision before speech has formed the basis of communication. Visual, audio, and behavioural communication models are among the forms of communication. These models has been allowed people to verbally and non-verbally convey the information they need during the communication phases throughout life. Over time, people have shaped and differentiated environmental conditions, culture, and forms of communication. These factors play an important role in the shaping and development of communication skills (Yaban, 2012).

\subsection{Design of Visual Communication}

The sense of sight is one of the most important senses. The events, existing objects and situations in the environment are defined by seeing them first and they are tried to be understood. Information obtained through the sense of sight is remembered more clearly than those obtained through other senses. For this reason, it can be easily stated that seeing comes before speaking (Han, 2014: pp. 1-3).

Communication regulates relationships of people with each other and allows them to exchange information. Communication can be done not only by talking, but also by hearing, touching, and seeing. Visual communication is seen as one of the most important ways of communication (Kavuran \& Cetinkaya, 2012: p. 611).

When we look at prehistorical times, wild animal paintings and hunting scenes drawn on cave walls are seen in the periods when there was no literacy. These are undoubtedly the first examples of visual communication. Even though the paintings drawn on the cave walls were researched much for what purpose and what was intended, it was understood that the main purpose was to communicate and express themselves. The most important purpose in these pictures is to transmit their messages to different societies (Becer, 2011: p. 28-29) (Figure 1).

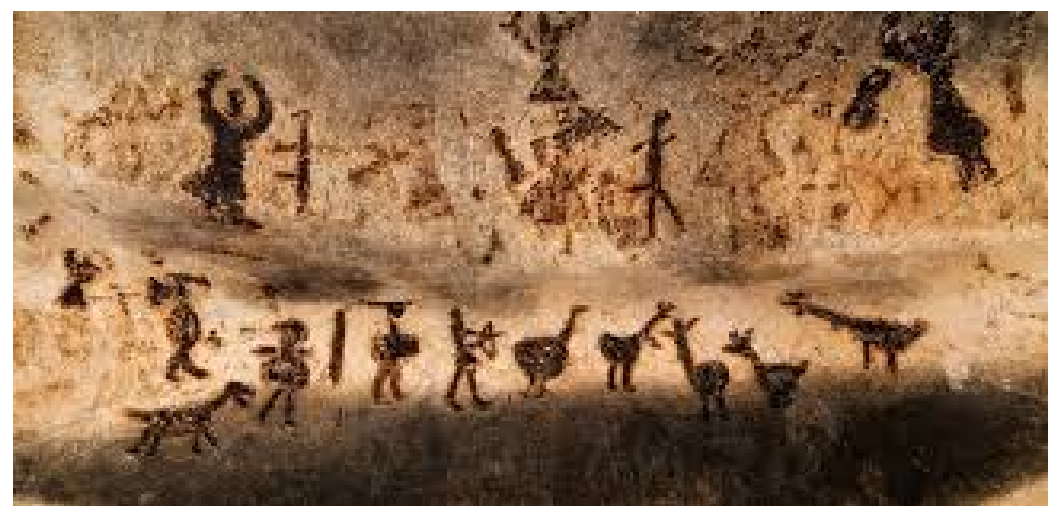

Figure 1. Animal and human figures drawn on cave walls. 
People carved animal forms into teeth and horns with sharp tools, using pigments and drawn pictures of animals on cave walls. The image shown above is an example that attracts attention. It is one of the first examples of this visual communication from 15,000 years ago. Before inventions that are important for communication such as alphabets, paper and printing presses, people expressed themselves with the means they had and created images that would live through the ages. Today, their drawings are a document and give information about the beliefs of our ancestors, the way they hunted, how they dressed, in other words, how they lasted their lives a long time ago.

The foundation of communication began with human history and has been evolved to this day. During the "palaeolithic" period, which is considered one of the first periods in human history when tools began to be used, it was seen that people drew pictures of herds of animals on the walls of caves where they took refuge for shelter and protection. Considering the similarity of the icons, logos, and emblems we use by stylizing today with the drawings on the cave walls, which are considered as the first examples of visual communication, it can be considered that it leads the work done today.

\section{Design in Visual Communication}

Today, when we experience that everything is temporary, high-speed communication has become a concept that expresses the way we connect with each other. Therefore, how we connect with instant viewers in terms of visual communication and how we maintain or will maintain this connection is one of the main problems we think about. The concept of communication can be defined as an exchange of emotions, thoughts, behaviours, and information between two groups of people or people called senders and recipients. Therefore, visual communication is a social process.

For visual communication purposes with contemporary, creative and aesthetic qualities, interaction is provided with various communication channels such as blogs, websites, posters, magazines, video games, advertisements, television channels, applications, movies, etc. Because the qualities mentioned create a positive value in terms of Visual Communication. Although each of these environments has a unique feature and interface, basically all of them use and share the tool we define as visual language.

Visual language offers principles for creating clear, catchy, and informative graphics. It examines the unique ways we can provide cognitive and emotional meaning (Malamed, 2009: p. 10). It can transmit facts and ideas in a wider and deeper range than almost all other communication tools (Kepes, 1995: p. 13).

We live in an environment shaped by images that express our conversations, thoughts, and feelings. In this environment which is full of visual elements, it is one of the inevitable consequences that the communication in the society is more visually oriented. People have been using images for information recording and communication since the era of cave paintings. When we consider 
this long process, the potential of visual culture to replace print culture is an idea that has profound effects as much as the transition from oral culture to print culture. Within the framework of these factors, Visual Communication is universal and international and has no boundaries such as language, vocabulary, and grammar. It can be perceived by the literate as well as the non-literate (Kepes, 1995: p. 13) (Figure 2). It is a form of non-verbal communication. In this respect, the London Metro map is one of the best examples of this definition. The creator of the London Metro map, Henry Beck, with the map he designed in 1932, both realized a universal visual expression and managed to look into the future from the eyes of the user from the time he lived. In this respect, the London Metro Map is important as it is an example of a global standard followed by many transportation networks we use today. This and many other examples show us that Visual Communication can be anything that expresses things beautifully and clearly.

Visual Communication is an important part of contemporary design that defines information communication today. Visual Communication is based on both the eye that performs the act of seeing and the brain that makes sense of all sensory information received (Lester, 2013: 5). The most important resource which focuces on Visual Communication theory is Sol Worth's book, which consists of a series of articles called Visual Communication Study. The main subject in Worth's studies and articles is the question of how meaning is conveyed through visual images. This question is still the most important in all our studies in the context of Visual Communication today. Worth defined the process of transmitting visual messages as "a social process in which signs are produced and transmitted, perceived and interpreted as messages."

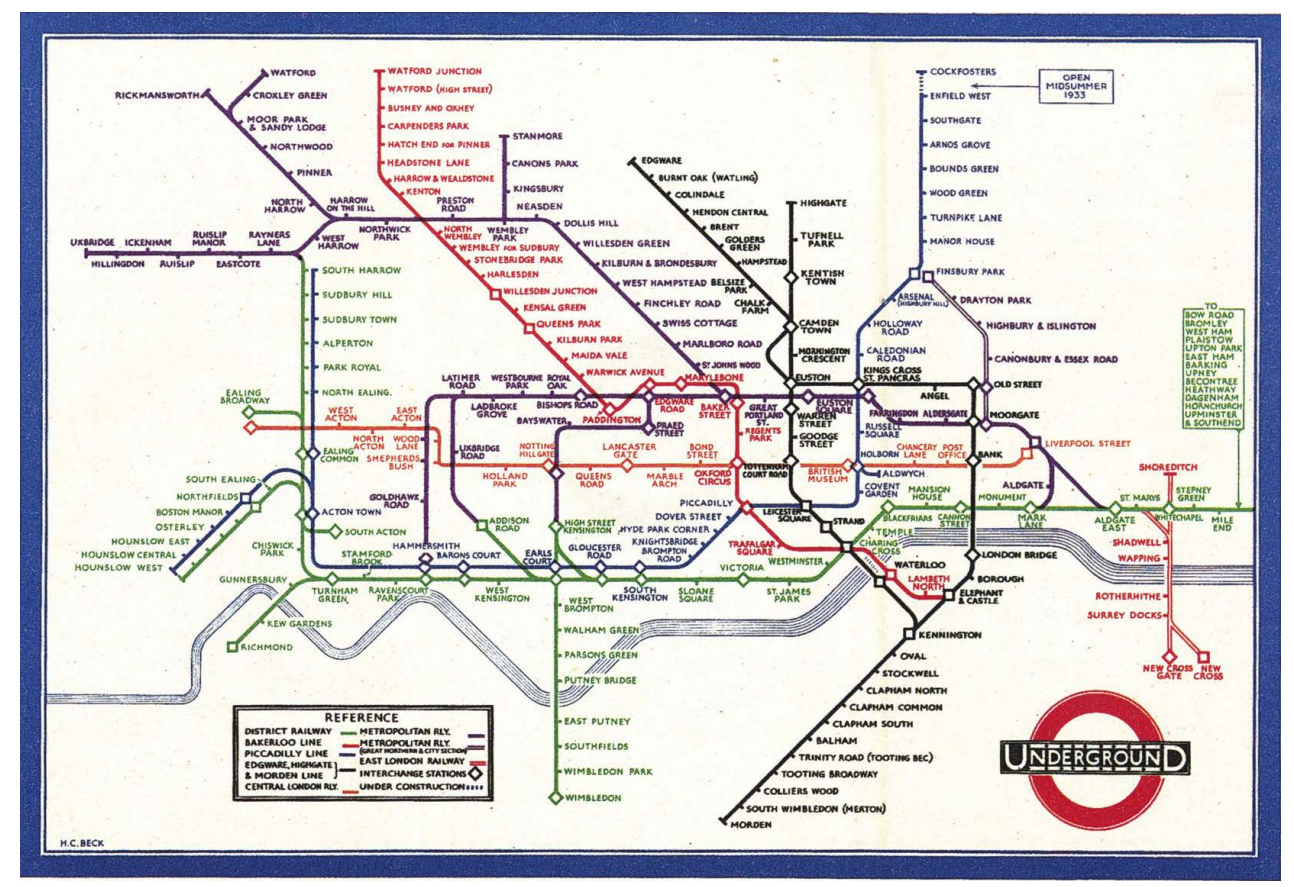

Figure 2. London metro map, Henry Beck, 1932. 
Visual communication through graphic and sign languages has long been taking place between people with different backgrounds and cultures and, in recent years, between human and machine (Huang et al., 2010: p. 7). When we look at the definitions of Visual Communication made in various periods, it is understood that there is not much change in the definitions. Although the world has gone through many stages of technological development during this process, it is clearly understood that the important point is to "transmit". Ultimately, it leads us to the model of Shannon and Weaver. The information source selects the information it wants to send to the desired destination. It transmits with the help of the tool. The message sent from the source turns into a signal. The tool receives and decodes the signal. It converts the decoded code back into a message and sends it to the destination. The received signal does not have to be the same as the signal sent by the source.

Designing is to invent, to project, to program, to make visible the invisible, and to communicate (Frascara, 2004: p. 2). According to Heskett, design can be defined as "the human capacity that shapes our environment to serve our needs and add meaning to our lives, using methods that are unprecedented in nature". Design is about ideas; it is needing and finding ideas, examining and defining their nature, and most importantly explaining and exemplifying them for understanding (Aspelund, 2010: p. 5). Design is the mediator between informing and understanding, having the role of making a complex topic clear and useful. The Visual Communication designer is the person who provides this interaction. The goal of visual communicator is not just to create a published image. The goal of the Visual Communication designer is to produce powerful pictures so that the viewer can remember the content of the visual (Lester, 2013: p. 7). Design is a problem-solving discipline. It takes into account more than the appearance of the designed product, but also the basic structure of the solution and the expected purchase by the users (Carliner, 2000: p. 563). In a similar way, Frascara emphasized the importance of the designer by saying "The important issue is not the communicative action itself, but its effect on knowledge, attitude, and people's behaviour" (Figure 3). In this context, the design of Grundy, an illustration designer, is a design that fully supports this explanation.

\subsection{Purpose of Design in Visual Communication}

Visual communication, which has become an integral part of social life, appears in every moment of individuals' lives. Nowadays, visual communication is applied in all kinds of media and it is not possible to avoid this communication (Han, 2014: p. 6).

The aims of visual communication design are briefly (Atan \& Polat, 2011: p. 49):

- Delivering the message to the desired target audience with a simple and simplified visual or visual integrity.

- Creating communication tools and elements that have a specific design concern, provided their originality. 


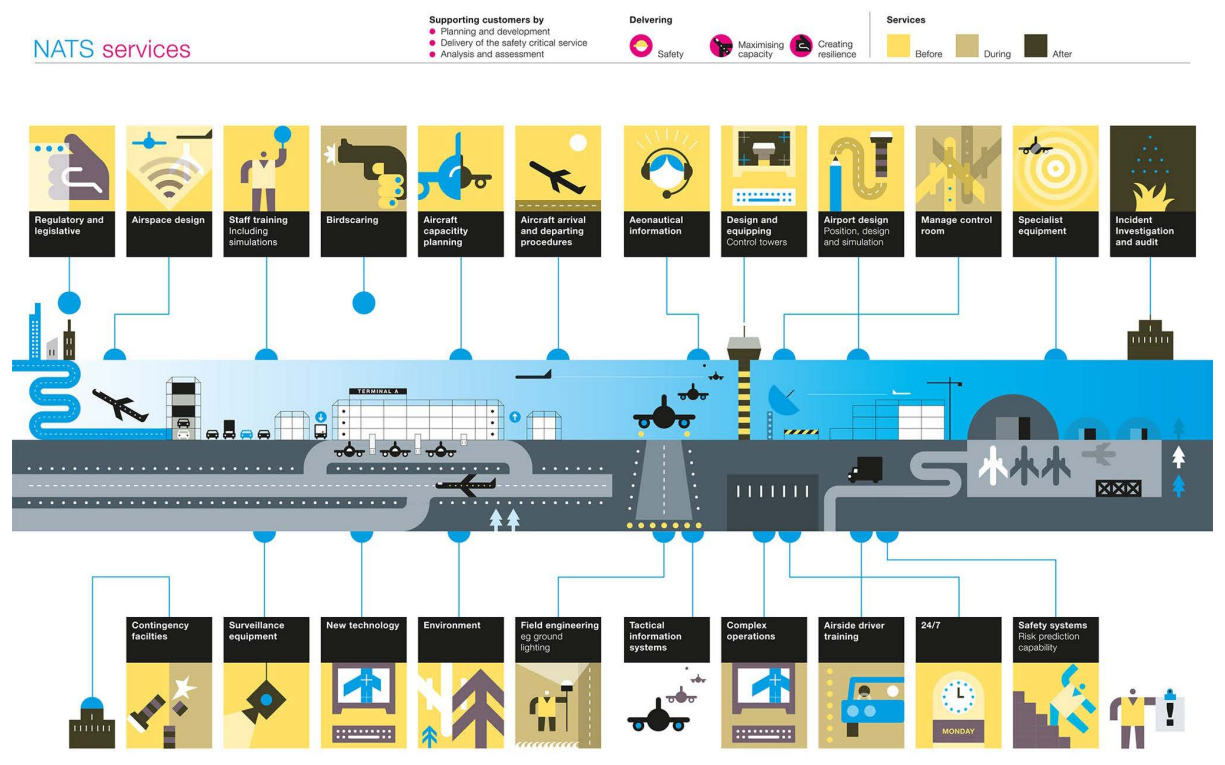

Figure 3. Peter Grundy, "NATS Services" (2008), diagram explaining Heathrow national air traffic services.

- Creating a striking and effective meaning power of the message that is intended to be transmitted to the mass.

- Thinking visually and intellectually in a straightforward manner within the scope of the subject.

- Instead of treating with general, usual logic, making interpretations that may be considered utopian by using straight, irrational, cross, and reverse logic.

- Being able to say strikingly what and why to say.

- Image pollution occurs with the development of visual communication design products with technology and the transformation of consumption into fashion. These graphic products, which cause visual pollution, can be evaluated as a result of fast consumption (Becer, 2011: p. 223).

\subsection{Design Products in Visual Communication}

All design products used in visual communication are called visual or audio media. A wide variety of visual communication products are used to reach target audiences in the media. These come across such as poster design, magazine design, illustration, and packaging logo designs. Today, the internet environment is mostly used to deliver these design products to the masses (Atan \& Polat, 2010: p. 170).

\subsubsection{Poster Design as a Visual Communication Product}

Posters are one of the important visual communication products used in the promotion of a product or service. It is the most effective way to reach people, although it is short-lived. When the typographic elements used in the advertising message on the poster are combined with the pictures and company signs, it is extremely effective on the target audience. As soon as the poster draws attention, 
it communicates with the target audience and thus fulfills its function.

Andy Warhol is one of the most prominent artists to use visual communication in the most effective and efficient way. This artist is known during his period as a painter, producer, and publisher. He is shown among the artists who use visual communication with the pop-art movement in the best way (Figure 4). Andy Warhol preferred to use visual communication mostly with poster designs and presented his messages to target audiences in this way (Çakır, 2014: pp. 37-38).

\subsubsection{Magazine Design as a Visual Communication Product}

Most magazines are the best media for high-quality and colour-printed advertising that allows for vibrant photos and eye-catching colours. Magazines usually sell with images rather than content (Figure 5). For this reason, people are happy to be visually stimulated. In this case, if the advertisement in the magazine is interesting, it may attract more people's attention (Han, 2014: p. 50).

There are very important steps before any magazine reaches its reader. The most important of these steps is to ensure that the target audience to be reached is impressed by its cover before they even read the magazine. Even though the information contained in the magazine affects the reader, first of all, it is necessary to impress with the cover of the magazine and ensure that it is purchased or curiousity. For this reason, magazine designs have always been affected by visual communication and continue to be affected.

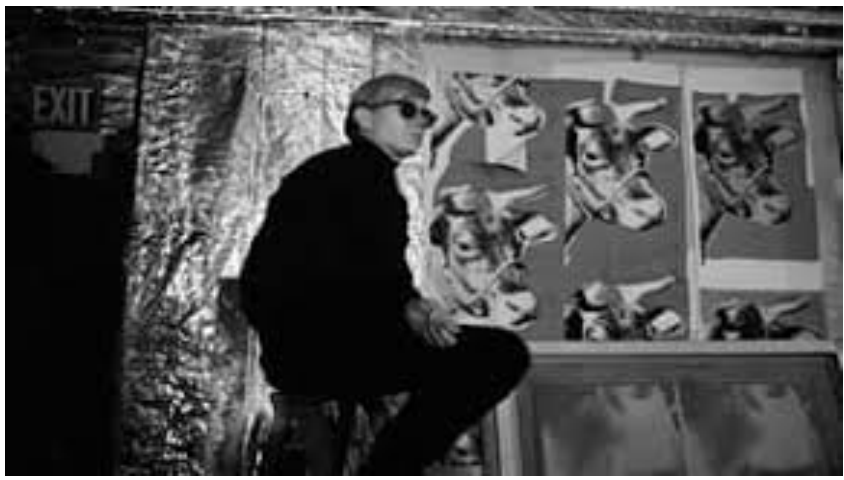

Figure 4. Andy Warhol, factory, New York.

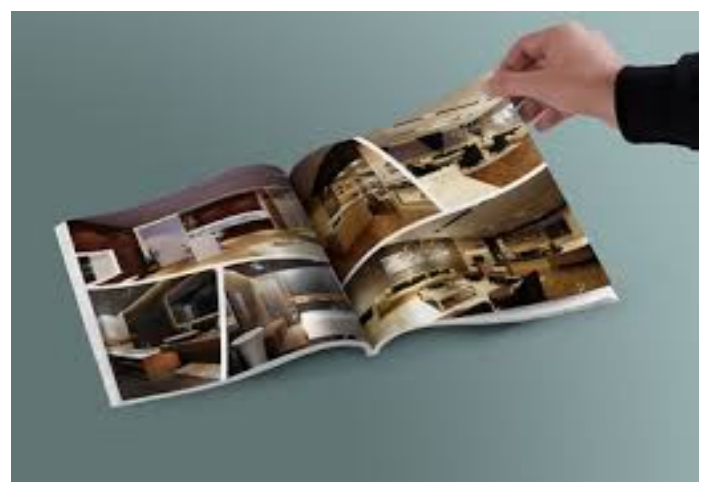

Figure 5. Magazine design as a visual communication tool. 


\subsubsection{Illustration as a Visual Communication Product}

Illustration means an explanatory picture in dictionary meaning. These are themed visualizations made in order to strengthen the titles and slogans, mostly the texts in the book by visually depicting and interpreting them and to ensure better understanding (Keskin, 2015: p. 15) (Figure 6). Since illustration created by drawing, painting or computer visualization techniques, emphasizing the subject rather than form is a type of painting that helps to understand any message in the most understandable way, it is seen that illustration is present in all areas of life.

Visual communication with illustration dates back to ancient times to cave wall paintings (Figure 7). As the periods progressed, illustration has managed to become an indispensable part of visual communication with the increase in print quality and reproduction techniques.

The golden age of illustration lasted from the 1880s to the end of the World War I. During this period, newspapers, magazines, and picture books were the most common mass media. Advances in printing technology have also led to the development of illustrations (Yücebaş, 2006: p. 69).

\subsubsection{Packaging Design as a Visual Communication Product}

Based on the origin of the word "packaging", it is defined as "a device that wraps something in order to protect or control it" (Durmaz, 2009: p. 11).

Packaging is a functional material used in the protection, transportation, and trigger of purchase desire for the product. One of the most important factors in

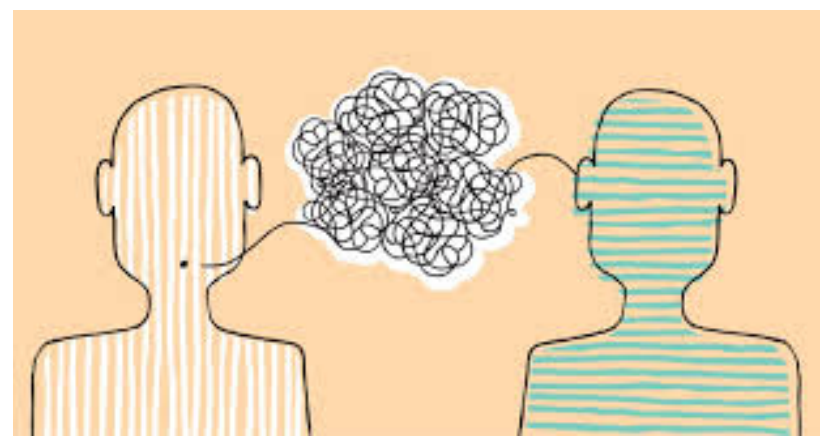

Figure 6. Illustration as a visual communication tool.

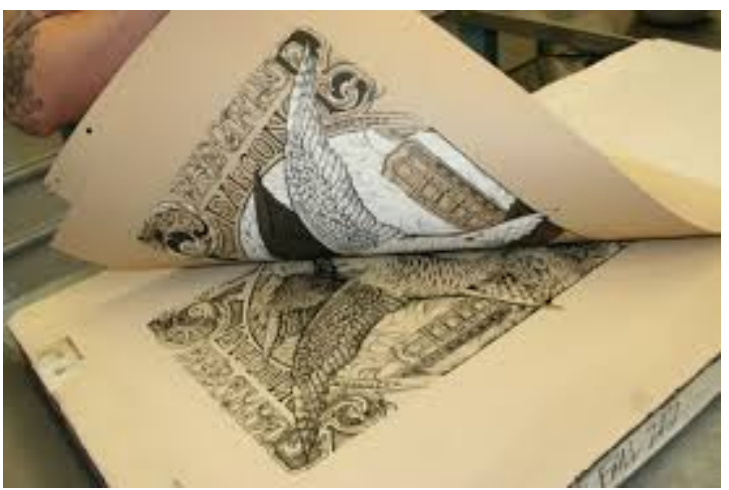

Figure 7. Illustration with lithography technique. 


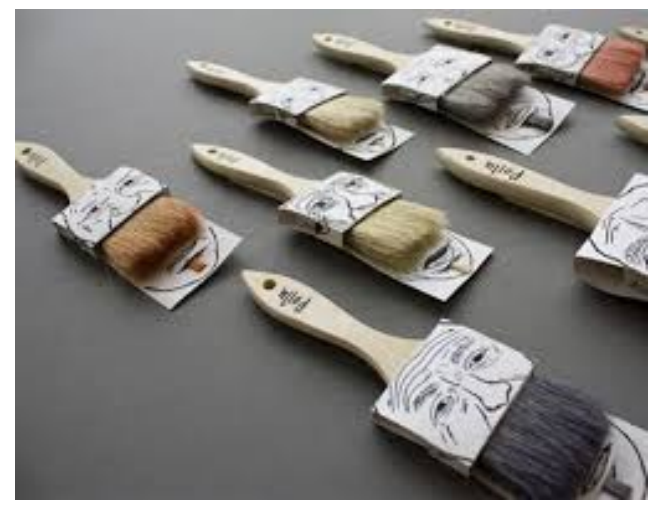

Figure 8. Packaging design as a visual communication tool.

promoting and purchasing the product is the design of the packaging (Düz, 2012: pp. 22-23) (Figure 8).

Another view which focuses the importance of packaging design is as follows; "For the consumer, packaging at the point of purchase represents the product" (Durmaz, 2009: p. 12). Studies show that the consumer makes a decision by looking at the packaging instead of its content when purchasing a product, and that packaging alone creates a quality perception (Becer, 2011: p. 206). Apple, one of the products branded with only its packaging, has become a brand with its simplicity (Durmaz, 2009: p. 12).

The purpose of the packaging designer is no different from his/her colleagues. $\mathrm{He} /$ she also aims to sell his/her client's product. According to Louis Cheskin, a marketing expert; "Designer has to sell the packaging and packaging has to sell the product" (Becer, 2011: p. 206).

\section{Conclusion}

Since the existence of humanity, the sense of sight has been the sense that is most useful for perception and attracts people's attention. Compared to other senses, people are much more affected by the sense of sight. The first ideas that sight is very important for humans were put forward by Aristotle in the Ancient Greek period. According to Aristotle, the sense of sight always comes before the sense of hearing. Interest in visual objects is always a priority for people.

Another important idea put forward today is that video messages are much more effective than audio messages. That is because people believe and are affected by what they see rather than what they hear. Visual objects are always able to keep people's attention high.

All kinds of information exchanges and interactions between people are a communication. When this exchange is performed with visuals, it is called visual communication. Spoken language is used when transmitting a feeling, thought, and information to someone else. Visual communication is the exchange of information created through the image between people without the need for words. The development of vision before speech has formed the basis of communication. Visual, audio, and behavioural communication models are among 
the forms of communication. These models has been allowed people to verbally and non-verbally convey the information they need during the communication phases throughout life. Over time, people have shaped and differentiated environmental conditions, culture, and forms of communication. These factors play an important role in the shaping and development of communication skills.

Guy Debord suggested that modern society can be defined as a "the society of spectacle" in the 1960s. According to him, people passively consume images and objects of spectacle that are disconnected from real life and real needs. Even people are reduced to images to be examined carefully.

From this point of view, technical programs have a great place in post-modern visual communication where the design is today. Although the technology that comes with the computer brings more technical convenience, it is thought that it brings about an intense visual inaccuracy and pollution in the application dimension. For this reason, in order for computers to work, sensitive, knowledgeable, sensible, and competent designers must sit behind them. The reason of it is that, whether aware or not, design pollution can affect people over time and update most of the mistakes and ugliness and make them ordinary.

From this point forth, the proposals and evaluations which can be offered in this study indeed support the fact that the place of technical programs at the point reached of design in visual communication in the post-modern period is a very important. Despite the technology coming along with the computers bring a great many facility in technical sense, it also brings about a lot of visual falses and pollution in the dimension of implementation. For such reason, so that the computers can serve the purpose, they must be operated by sensitive, knowledgeable, intuitive and authorized designers and this can be stated among the most significant conclusions of the research. Because, even if the persons are not aware of them, the design pollutions can affect the persons gradually, and may update and cause to be perceived as ordinary a great deal of falsies and penties.

\section{Conflicts of Interest}

The author declares no conflicts of interest regarding the publication of this paper.

\section{References}

Arıkan, G. (2009). Image-to-Print Graphic Design. Konya: Eğitim Academic Publications. Aspelund, K. (2010). The Design Process. New York: Fairchild Books.

Atan, U. (2017). What to Expected from the Visual Communication Designer. Konya: Selçuk University Faculty of Fine Arts.

Atan, U., \& Polat, A. A. (2010). General Situation Review of Billboards among Outdoor Advertising Tools in Konya Provincial Centre, Diyarbakır. Journal of Social Sciences Research, 8, 12-28.

Atan, U., \& Polat, A. A. (2011). How Should the Visual Communication Designer Be? Ankara: Gazi University.

Becer, E. (2011). Communication and Graphic Design. Ankara: Dost Bookstore Publica- 
tions.

Çakır, Ş. (2014). Modern Painting Art and Graphic Design Relationship. Master's Thesis, İstanbul: Istanbul Arel University.

Carliner, S. (2000). Physical, Cognitive, And Affective: A Three-Part Framework for Information Design. Technical Communication, 47, 561-576.

Durmaz, Ö. (2009). Associative Learning and Colour Decisions in Packaging Designs of Fast Moving Consumer Goods. Master’s Thesis, Izmir: Dokuz Eylül University.

Düz, N. (2012). Packaging-Advertising Relationship and Its Place in Design Education. Suleyman Demirel University Journal, 3, 25-36.

Erdal, T. (2006). Examining the Effects of Gestalt Theory on Graphic Design. Kocaeli: Kocaeli University Publications.

Eroğlu, E. (1996). Media-Message-Method Relationship in Communication Process and Transition from Traditional Education to Distance Education Systems. Kurgu Journal, 3, 1-13.

Frascara, J. (2004). Communication Design: Principles, Methods and Practice. New York: Allworth.

Han, B. (2014). Visual Effects of Advertisements. Master's Thesis, Istanbul: Istanbul Arel University Institute of Social Sciences, Department of Graphic Design.

Huang, M. L., Nguyen, Q. V., \& Zhang, K. (2010). Visual Information Communication. New York: Springer. https://doi.org/10.1007/978-1-4419-0312-9

Kavuran, T., \& Çetinkaya, A. (2012). Graphic Analysis of Movie Posters in Terms of Visual Communication. Evaluation of Cinema Film Posters Awarded at Antalya Golden Orange Film Festival between 2000-2010. 2. International Communication Symposium: Kyrgyzstan Turkey Manas University Publications.

Kepes, G. (1995). Language of Vision. Mineola, NY: Dover Publication.

Keskin, E. (2015). Technical Illustrations in the Field of Mechanics from Yesterday to Today. Master's Thesis, Istanbul: Istanbul Arel University.

Lester, P. M. (2013). Visual Communication: Images with Messages. Belmont, CA: Wadsworth.

Malamed, C. (2009). Visual Language for Designers: Principles for Creating Graphics That People Understand. Beverly, MA: Rockport.

Öztuna, H. A. (2007). Basic Design in Visual Communication. Istanbul: Yorum ve Sanat Publishing.

Parsa, A. F. (2004). The Power of Image and the Rise of Visual Culture. Izmir: Ege University Faculty of Communication Publications.

Uçar, T. F. (2004). Visual Communication and Graphic Design. İnkılap Bookstore.

Yücebaş, Ç. (2006). Relationship between Typography and Visuals in Visual Integrity Creation and Its Place in Art Education. Doctorate Thesis, Izmir: Dokuz Eylül University. 